\title{
EDITORIAL
}

\section{Extracorporeal lung assist: more than kicking a dead horse?}

\author{
M.M. Hoeper and T. Welte
}

$\mathbf{U}$ $\mathrm{p}$ to now, the history of extracorporeal lung support has been a tale of great expectations and even greater disappointments. In 1972, HiLl et al. [1] published the first case report on the use of extracorporeal membrane oxygenation (ECMO) in a young patient who suffered from acute respiratory distress syndrome (ARDS) after trauma. At that time, mortality rates from ARDS were extremely high and thus this report was embraced with great enthusiasm. However, only 2 yrs later reality caught up when the results of a randomised controlled trial using ECMO in ARDS were published showing mortality rates of $>90 \%$ in both treatment arms [2].

Despite these sobering results, several groups of investigators continued to work on extracorporeal devices. GATTINONI and co-workers $[3,4]$ were the first to introduce the use of extracorporeal $\mathrm{CO}_{2}$ removal to support protective ventilation strategies, now with survival rates of $\sim 50 \%$ among patients with ARDS. However, once again a randomised controlled trial failed to show a survival benefit in ARDS patients treated with extracorporeal $\mathrm{CO}_{2}$ removal [5] although the survival rates ( $33 \%$ in the extracorporeal group versus $42 \%$ in the conventional ventilation group) were now substantially better than in the 1970s.

The reasons for the failure to demonstrate a survival benefit with extracorporeal lung support were certainly manifold. The study by MoRris et al. [5] included only 40 patients and was gravely underpowered (for comparison, the ARDS Network trial on low tidal volumes recruited $>800$ patients before a survival difference of $22 \%$ became statistically significant [6]). More importantly, the technical devices used at these times were not sufficiently developed and therefore prone to complications, such as thrombosis, haemorrhage and infections. In addition, protective ventilation strategies differed substantially from what is being used today. For example, in one of their first studies, GATTINONI et al. [4] used a ventilatory concept based on low breathing frequencies and high tidal volumes. Nowadays, this approach wouldn't be considered lung protective as it has been shown that low tidal volumes

Dept of Respiratory Medicine, Hannover Medical School, Hannover, Germany.

STATEMENT OF INTEREST: A statement of interest for M.M. Hoeper can be found at www.erj. ersjournals.com/misc/statements.shtml

CORRESPONDENCE: M.M. Hoeper, Hannover Medical School, Dept of Respiratory Medicine, CarlNeuberg-Str. 1, 30625 Hannover, Germany. Fax: 49 5115328536.E-mail: hoeper.marius@mhhannover.de and airway pressure gradients are the key determinants of a protective ventilatory strategy [6-8].

So, why is it that extracorporeal devices are probably being used more frequently than ever before in modern intensive care units? There are several explanations for this including the availability of much better devices which are less prone to complications and more convenient to use. In addition, we have a better understanding of the physiology of extracorporeal devices and can tailor their use to the needs of individual patients. Conventional veno-arterial ECMO is now utilised mainly in patients in need of full cardiopulmonary support. Patients with severe oxygenation failure are candidates for veno-venous lung support. Patients presenting predominantly with hypercapnic respiratory failure may be treated with an arterio-venous assist device. Both the veno-arterial and the veno-venous approach require the use of a pump to generate flow rates of $3-5 \mathrm{~L} \cdot \mathrm{min}^{-1}$ to ensure sufficient organ perfusion and oxygenation, respectively. In contrast, no pump is needed for the arterio-venous approach since low-resistance devices are available which allow sufficient blood flow driven by the patient's own blood pressure. These so-called pumpless extracorporeal lung assist (pECLA) devices achieve flow rates of $0.8-1.5 \mathrm{~L} \cdot \mathrm{min}^{-1}$ which is sufficient to allow effective $\mathrm{CO}_{2}$ removal. Vascular access is usually obtained with $13-15 \mathrm{~F}$ arterial cannulas and 15-17F venous cannulas inserted into the femoral vessels.

The pumpless arterio-venous approach is increasingly being used in patients with ARDS, although there is still no data from randomised controlled trials to support this concept. However, the results of the ARDS Network have demonstrated that a less invasive ventilation strategy with low tidal volumes of $6 \mathrm{~mL} \cdot \mathrm{kg}^{-1}$ and inspiratory plateau pressures of $30 \mathrm{cmH}_{2} \mathrm{O}$ $(3 \mathrm{kPa})$ resulted in a better survival rate than what was considered conventional ventilation at that time, i.e. tidal volumes of $12 \mathrm{~mL} \cdot \mathrm{kg}^{-1}$ and inspiratory plateau pressures up to $50 \mathrm{cmH}_{2} \mathrm{O}(5 \mathrm{kPa})$ [6]. Data from experimental models suggest that even lower tidal volumes and plateau pressures might be more beneficial [9] but in real life, protective ventilation is often limited by hypercapnia and respiratory acidosis. Although hypercapnia by itself has not been associated with adverse consequences, it may be extremely distressing for the patient, resulting in poor patient-ventilator interaction, the need for intensified analgosedation or even relaxation and an increasing use of catecholamines.

BEIN et al. [10] have reported the largest series on the use of pECLA in 90 patients with ARDS. Although this study was 
noncontrolled, it confirmed the concept that pECLA can be used to ensure protective ventilation. In that study, survival rates were lower than expected but this does not prove that pECLA was responsible for improved survival. Another study demonstrated that pECLA can be used successfully to bridge patients with end-stage lung disease to transplantation [11]. However the use of pECLA may be harmful as it is associated with significant complications, foremost lower limb ischaemia, compartment syndromes and cannula thrombosis [10].

In the present issue of the European Respiratory Journal, HOMMEL et al. [12] report on four patients with ARDS and bronchopleural fistulas with persistent air leakage despite surgical interventions. These patients usually have a poor prognosis if they develop respiratory failure and require mechanical ventilation with high airway pressures. In all four patients, the use of pECLA corrected hypercapnia and enabled the reduction of airway pressures, and all patients were eventually discharged from the hospital. As Hommel et al. [12] point out in their paper, there is no proof that the use of pECLA was responsible for the good outcome but there are compelling pathophysiological reasons supporting this hypothesis.

What are the main obstacles for the future development of extracorporeal lung assist? Many would argue that we need data from randomised controlled trials to warrant the use of such invasive, costly and potentially dangerous devices. In fact, such trials are currently underway but it will take years until results become available and the question remains as to whether these trials are adequately designed and powered to demonstrate an improved outcome. Unfortunately, those patients who might benefit the most from extracorporeal lung support may be too ill to be eligible for randomised controlled trials. Even in modern intensive care medicine many of our decisions are based on experience and pathophysiological considerations rather than on evidence from rigorous trials, and this must not necessarily be a bad thing. In the setting of intensive care medicine, randomised controlled trials often enrol heterogeneous patient populations. If those trials fail, a drug or intervention is usually considered not effective although it may still be useful in selected patients. The study by Hommel et al. [12] is a good example of a judicious use of an experimental device based on a sound clinical and pathophysiological rationale. Until further data become available it seems to be crucial to limit the use of such devices to wellequipped intensive care units with extensive experience in managing patients with severe ARDS. Similar to other areas in medicine, volume matters and the whole team needs substantial experience with the use of these devices to avoid the numerous pitfalls and to manage potentially dramatic complications.

Extracorporeal lung assist is not dead; in fact it seems to be more alive than ever. However, for the time being, the use of pumpless extracorporeal lung assist and other extracorporeal devices should be restricted to specialised centres, mostly tertiary care hospitals. It is likely that such devices improve the management of selected patients with respiratory failure as described in the case series by HommeL et al. [12] but they may also cause substantial harm when they are not being used in a proper setting.

\section{REFERENCES}

1 Hill JD, O’Brien TG, Murray JJ, et al. Prolonged extracorporeal oxygenation for acute post-traumatic respiratory failure (shock-lung syndrome). Use of the Bramson membrane lung. N Engl J Med 1972; 286: 629-634.

2 Zapol WM, Snider MT, Hill JD, et al. Extracorporeal membrane oxygenation in severe acute respiratory failure. A randomized prospective study. JAMA 1979; 242: 2193-2196.

3 Gattinoni L, Kolobow T, Tomlinson T, et al. Low-frequency positive pressure ventilation with extracorporeal carbon dioxide removal (LFPPV-ECCO2R): an experimental study. Anesth Analg 1978; 57: 470-477.

4 Gattinoni L, Agostoni A, Pesenti A, et al. Treatment of acute respiratory failure with low-frequency positivepressure ventilation and extracorporeal removal of $\mathrm{CO}_{2}$. Lancet 1980; 2: 292-294.

5 Morris AH, Wallace CJ, Menlove RL, et al. Randomized clinical trial of pressure-controlled inverse ratio ventilation and extracorporeal $\mathrm{CO}_{2}$ removal for adult respiratory distress syndrome. Am J Respir Crit Care Med 1994; 149: 295-305.

6 Ventilation with lower tidal volumes as compared with traditional tidal volumes for acute lung injury and the acute respiratory distress syndrome. The Acute Respiratory Distress Syndrome Network. N Engl J Med 2000; 342: 1301-1308.

7 Amato MB, Barbas CS, Medeiros DM, et al. Effect of a protective-ventilation strategy on mortality in the acute respiratory distress syndrome. N Engl J Med 1998; 338: 347-354.

8 Villar J, Kacmarek RM, Perez-Mendez L, Aguirre-Jaime A. A high positive end-expiratory pressure, low tidal volume ventilatory strategy improves outcome in persistent acute respiratory distress syndrome: a randomized, controlled trial. Crit Care Med 2006; 34: 1311-1318.

9 Carney D, DiRocco J, Nieman G. Dynamic alveolar mechanics and ventilator-induced lung injury. Crit Care Med 2005; 33: Suppl. 3, S122-S128.

10 Bein $\mathrm{T}$, Weber F, Philipp A, et al. A new pumpless extracorporeal interventional lung assist in critical hypoxemia/hypercapnia. Crit Care Med 2006; 34: 1372-1377.

11 Fischer $\mathrm{S}$, Simon $\mathrm{AR}$, Welte $\mathrm{T}$, et al. Bridge to lung transplantation with the novel pumpless interventional lung assist device NovaLung. J Thorac Cardiovasc Surg 2006; 131: 719-723.

12 Hommel M, Deja M, von Dossow V, et al. Bronchial fistulae in ARDS patients: management with an extracorporeal lung assist device. Eur Resp J 2008; 32: 1652-1655. 